\title{
Combined Application of Composite Powders WC-Co and Additives of Nanoparticles as an Effective Method of Improving the Properties of Hard Metals
}

\author{
Yuri I.Gordeev ${ }^{1, a^{*}}$, Vitaly B.Yasinski ${ }^{1, d}$, Aleksandr S.Binchurov ${ }^{1, c}$, \\ Nikolay E. Anistratenko ${ }^{1, a}$, Irina V. Nikolaenko ${ }^{2, d}$ \\ ${ }^{1}$ Polytechnic Institute, Siberian Federal University, Kirenskiy Str. 26, Krasnoyarsk, 660074, Russia \\ ${ }^{2}$ Institute of Solid State Chemistry of the Ural Branch of the Russian Academy of Sciences, \\ Pervomaiskaya Str. 91, Ekaterinburg, 620990, Russia
}

atms-mtf@rambler.ru, dVYasinskiy@sfu-kras.ru, ${ }^{\mathrm{c}}$ mexanixs@mail.ru, ${ }^{d}$ nikolaenko@ihim.uran.ru

Keywords: Hardmetal composites, nanoparticles, composite powders, nanostructured materials, microstructure parameters, strength and fracture toughness.

\begin{abstract}
The results of experimental studies show that the use of composite powders (WC-Co) in combination with the modification by the additives of ceramic nanoparticles allows controlling the parameters of the microstructure and increasing the strength of the binder and the level of physical and mechanical properties of the hard metal in general. The coating of carbide particles with a layer of a binder is an effective starting method that allows to obtain a bulk compound that preserves the unique properties of the initial nanopowders and ensures a uniform distribution of the phases (WC, $\mathrm{Co}, \mathrm{Al}_{2} \mathrm{O}_{3}$ ). Such multiphase fragmentary nanostructured composite is characterized by additional heterogeneity, determined by the differences in size and elastic properties of the phases. By combining the sizes and properties of the phase components in such heterogeneous composite, it is possible to increase the fracture energy (i.e. Palmqvist fracture toughness) up to $20-22 \mathrm{MPa} \cdot \mathrm{m}^{1 / 2}$ as a result of inhibition on inclusions of nanoparticles the stress relaxation and change in the trajectory of the intergranular crack. Based on the proposed stereological models and experimentally established relationships between composition and microstructure parameters, the required volume concentrations of nanoparticles' additives and composite powders (WC-Co) were determined.
\end{abstract}

\section{Introduction}

It is well known that for conventional methods of obtaining a high density of WC-Co sintered material, a high sintering temperature, usually in a liquid sintering state, and a long residence time are usually used. As a result, the size of the WC grains in the compacted volume can increase at the micrometer scale, even if the initial particle of the powder was nanosized. Therefore, in order to obtain a volumetric product with the properties of isolated nanoparticles, it is necessary to avoid or at least reduce their chemical interaction, agglomeration and recrystallization $[1,2]$. There are known effective methods and processing technologies enabling the retention of submicron carbide grains due to introduction of nanosized powders of vanadium, chromium, tantalum carbides or other nanopowders of oxides, nitrides which act as growth inhibitors of the main phase WC in sintering process [3]. In [4] it is shown that the efficiency of modification of the hard metals by nanoparticles of inhibitors $\mathrm{Al}_{2} \mathrm{O}_{3}$ substantially depends on the size, concentration and volume fraction of all components of $\mathrm{WC}-\mathrm{Co}-\mathrm{Al}_{2} \mathrm{O}_{3}$ composite. Excessive concentration of nanoparticles in the local volume between carbide grains increases the degree of contact and the formation of agglomerates. During the sintering of heterogeneous hardmetal composites, the interfacial energy changes, due to decrease in specific surface area of nanodispersed phases, followed by their coagulation. Coating of carbide particles by a binding layer is also a starting method which allows to obtain volumetric work pieces with the retention of unique properties of the initial nanopowders [5]. Technologically it is possible to apply a binding layer on every carbide particle of the powder preliminarily or to obtain WC-Co composite powder by different methods, such as spray conversion process, 
mechanical alloying, co-precipitation, consecutive chemical reactions, two-step processing, etc. [1, 2]. This work introduces the new concept of coated fine carbides, modified by nanoparticles $\mathrm{Al}_{2} \mathrm{O}_{3}$ (inhibitors), as starting method for high statistical homogeneity of the relative distribution of nanoparticles (inhibitors) in the cobalt binder between carbide grains and the formation of nanostructured inclusions in hard metal composites and improvement of hardmetals properties. The prevention of a carbide grains' growth is possible in the process of subsequent compaction of composite powders and lower temperature sintering.

\section{Material and methods}

The morphology and microstructure of the powder and the sintered volume were observed using a scanning electron microscope JEOL JSM-7001F (SEM). The particle size distribution of initial and mixed powders was determined by laser diffraction using SALD-7101 Shimadzu device and a scanning electron microscope. The microstructure of samples was examined on the polished surfaces by means of Hitachi TM1000 and JEOL JSM-7500FA scanning electron microscopes. The fractures analyses were carried out using JAMP 9500F microscope. The following mechanical properties were determined: the hardness HV30 and fracture toughness by indentation Palmqvist method using a Vicker's Hardness Tester (AVK-A, AKASHI) with a load of $30 \mathrm{kgf}$. The strength of a transverse rupture (fracture) of a bulk sample was determined by a three-point bending test (Shimadzu AG-IS $100 \mathrm{kN}$ ). Nanopowders obtained by shock-wave synthesis or by electric explosion were used as strengthening additives for hard metals. The morphology of the powders is shown in Fig. 1, the average particle size ranged from $0,067-0.1 \mu \mathrm{m}$ for $\mathrm{Al}_{2} 0_{3}$. Composite powders (WC-Co) with particle size 200-400 nm were synthesized by a combination of two methods: liquid-phase precipitation on a carbon support and low-temperature microwave heat treatment in argon stream [6]. Cobalt was introduced into the precursor in the precipitation stage before heat treatment, and its content in the composite was $9 \%$. The specific surface area of the materials was measured using the BET method in automatic mode by means of a TriStar 3020 analyzer (Micromeritics, USA). The specific surface of nanopowders was in the range from 8 to $20 \mathrm{~m}^{2} / \mathrm{g}$ for ceramic and about $6 \mathrm{~m}^{2} / \mathrm{g}$ for tungsten carbide doped with cobalt.

\section{Results and discussion}

The carbide composites, which were studied in this work, are complex heterogeneous by their structure materials with at least one phase exhibiting the properties of the nanomaterial. It was shown in the works $[4,8]$ that the efficiency of the modifying hard metals with $\mathrm{Al}_{2} \mathrm{O}_{3}$ nanoparticles depends significantly on the sizes, concentration and volume fractions of all WC-Co- $\mathrm{Al}_{2} \mathrm{O}_{3}$ composites particles. In the case of random voids filling between carbide grains, various structural fragments can be formed by oxide particles, that have different degrees of contact and internal microporosity can form. Conditionally, fragments between carbide grains can be represented in the form of three basic structure types.

Type 1. Isolated inclusions of nanoparticles are formed with a small concentration of nanoparticles' additives in the local volume of the cobalt interlayer. The implementation of fragments of this type of WC-Co nanoparticle composite structures is the most favorable topic from the perspective of the known mechanisms of dispersion hardening of metals. Isolated and statistically uniformly distributed nanoparticles which were introduced into the binder interlayer, contribute to decreasing its thickness. The choice of the effective thickness of the cobalt layer $\lambda$ eff was carried out on the basis of the probabilistic approach, based on the model, described in more details in [4] and various possible options of crack propagation through interlayer depend on the content and size of nanoparticle additives. It was assumed that the material in a cobalt single volume between carbide grains, modified by nanoparticles, is dispersibly hardened, so the strength of such binder material modified by the nanoparticles additives, is much higher than the cobalt base material has. 
Type 2. Aglomerates from nanoparticles. With an increase in the nanoparticles concentration in the local volumes between carbide grains, due to insufficient uniformity in the components mixing, the degree of their contactness and the agglomerates formation with a developed internal microporosity increases. During the process of the polydisperse hard metal composites sintering, the change in interfacial energy occurs primarily due to decrease of the specific nanodispersed phases surface area, which is accompanied by their agglomeration and possible subsequent coagulation (Fig. 1). Electron microscopic studies show that the real microstructure parameters differ from the model parameters.

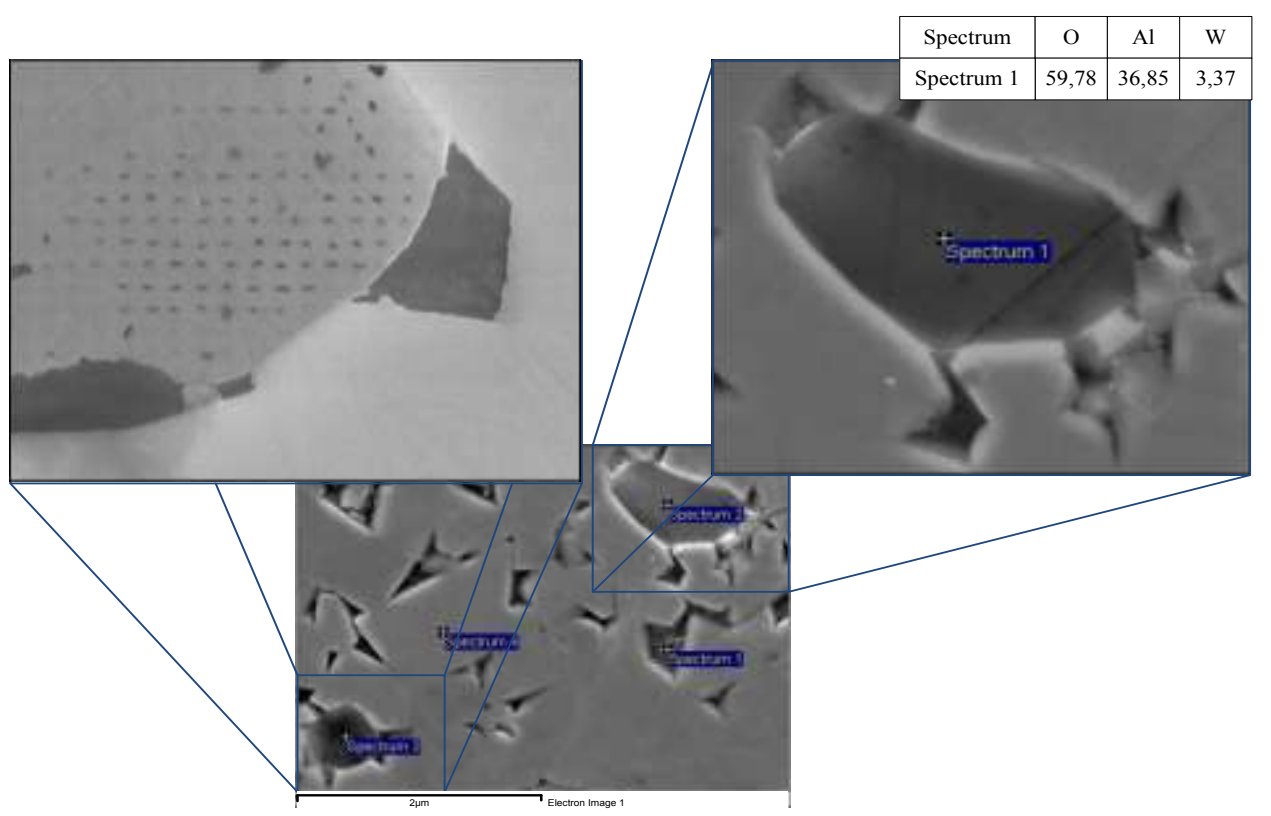

\begin{tabular}{|c|c|c|c|c|c|}
\hline Spectrum & C & O & Al & Co & W \\
\hline Spectrum 1 & 13.40 & 3.65 & 1.17 & 74.54 & 7.25 \\
\hline Spectrum 2 & - & 58.94 & 37.08 & 0.71 & 3.27 \\
\hline Spectrum 3 & - & 57.02 & 31.32 & 6.16 & 5.50 \\
\hline Spectrum 4 & 46.03 & - & - & - & 53.97 \\
\hline
\end{tabular}

Fig. 1. The Evolution of the nanoparticle agglomerates to differend structures

This is quite understandable on the basis of physical considerations. However, these structural metamorphoses are, to some extent, unavoidable with the traditional methods of mixture production, which are widely used in the production of hard metals. The presence of such fragments is illustrated by the results of the microstructure investigation. The fragment of the structure is an illustration of the effect of nanoparticles' self-organization to a quasinanostructured (boundary) state between the agglomerate and the crystallite.

Type 3. Polydesperse heterogeneous structure. The actual microstructure of the carbide composites, modified by nanoparticles, is heterogeneous and patchy in the distribution and morphology of the additional oxide phase which was formed from the nanoparticles. The formation of different types of structures can occur simultaneously depending on the different concentration of nanoparticles in local volumes between the grains of the basic carbide phase. During the sintering process, various competing homogenization processes are realized, and their transformations also occur. This is confirmed by the results of our own electron microscopic studies of the microstructure and the data of other authors [1 - 3]. Typical images of microstructures from the polished surfaces of the samples are shown in Fig. 2. At the microscopic (micron) level, the statically and homogeneously distributed on the material volume structural fragments, described above in the combination, form a new composite of a more complex level. Such a multiphase 
composite is characterized by additional heterogeneity, due to differences in the elastic phases characteristics. This is manifested in the heterogeneity of the stress-strain state during liquid-phase sintering during the manufacturing process (along the interfaces, during shrinkage, compaction) and with external mechanical action on the compacted material. In particular, this is confirmed by the research data on the material toughness destruction by the Palmqvist method in the combination with the microstructure studying. The cracks which appear in the material as a result of the indenter introduction (the Vicker's diamond pyramid) attract attention mainly because they are potential carriers of the indirect information about the strength and material operational stability, reflect changes in the destruction mechanisms, corresponding to different types of structures. Due to the strengthening effect of the binder phase by inclusions of nanoadditives, the stress concentration of the crack tip will be resolved through plastic deformation; thus, the cracks don't continue extend (Fig. 2).

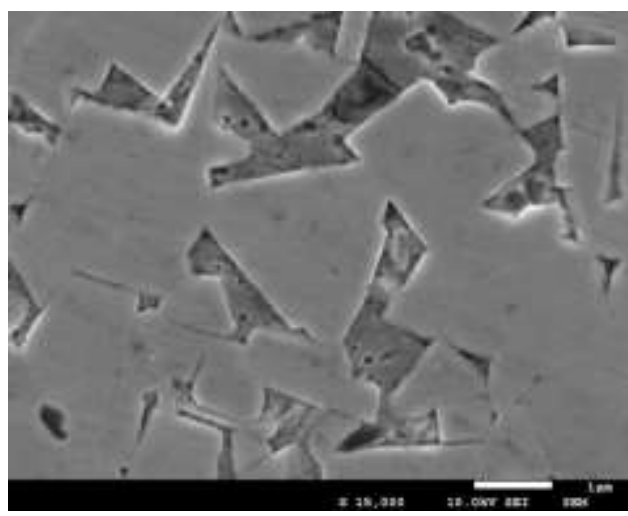

a)

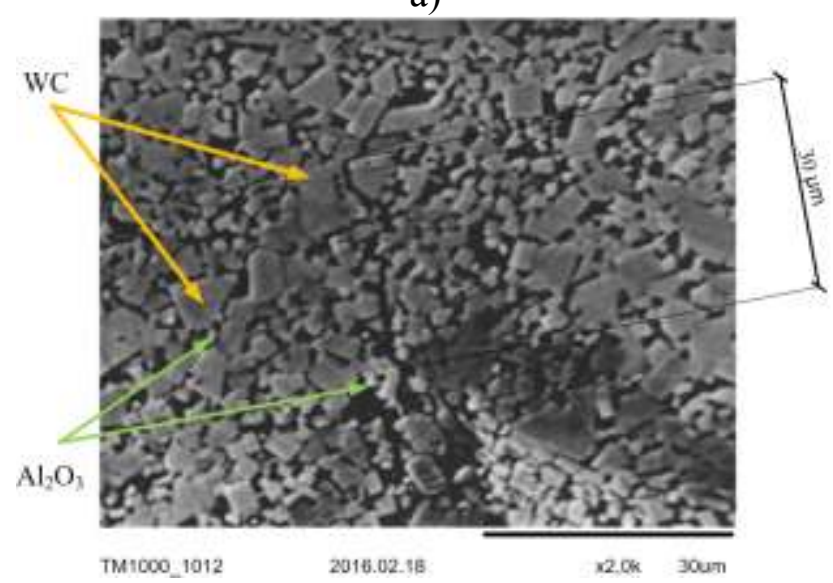

c)

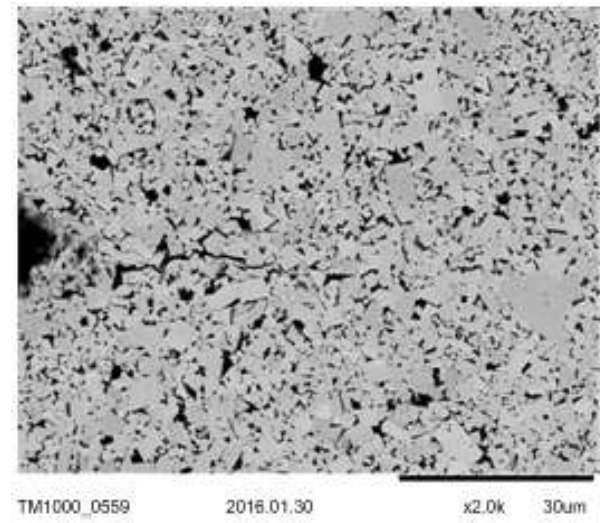

b)

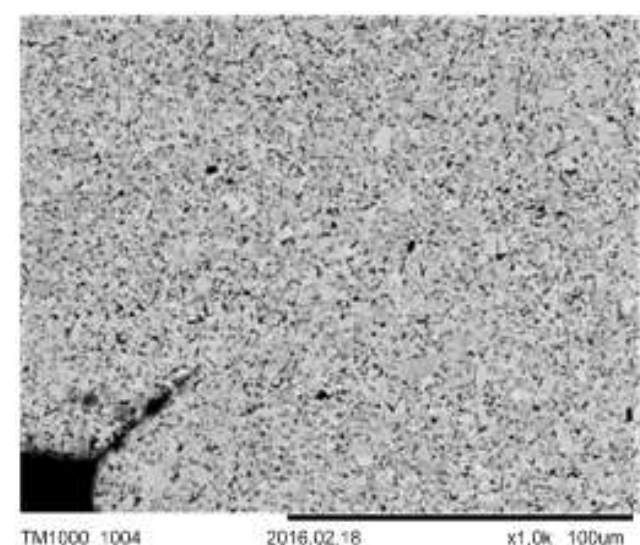

d)

Fig. 2. Nature of crack propagation from the corner of the Vicker's pyramid imprint $(a, b)$ fracture inhibition on the nanoparticles inclusions (the metal of the bond from the surface of the polished section is removed by etching) (c); the relaxation of stresses in the front propagation of the crack (contrast etching of the section) (d)

Meanwhile, the binder phase can link together the two crack faces through the bridging process. The bridging effect was also observed between $\mathrm{WC}-\mathrm{Al}_{2} \mathrm{O}_{3}$ phases, the crack propagation path was not obviously affected. This result corresponds to the tortuosity phenomenon. Consequently, the bridging process suppressed the crack propagation and resulted in the increase of tortuosity. It should be emphasized that the appearance of discrete cracks approximately corresponds to the range of particle additions to $0.2 \%$ by weight. Similar changes in the mechanisms of destruction of carbide nanostructured composites in the propagation of cracks are indicated in the results of research [9]. So, despite the heterogeneity of the structure of a real three-phase composite and the 
presence of different fragments types, the overall integral level of physico-mechanical properties in the field of optimal additives increases (Fig. 3).

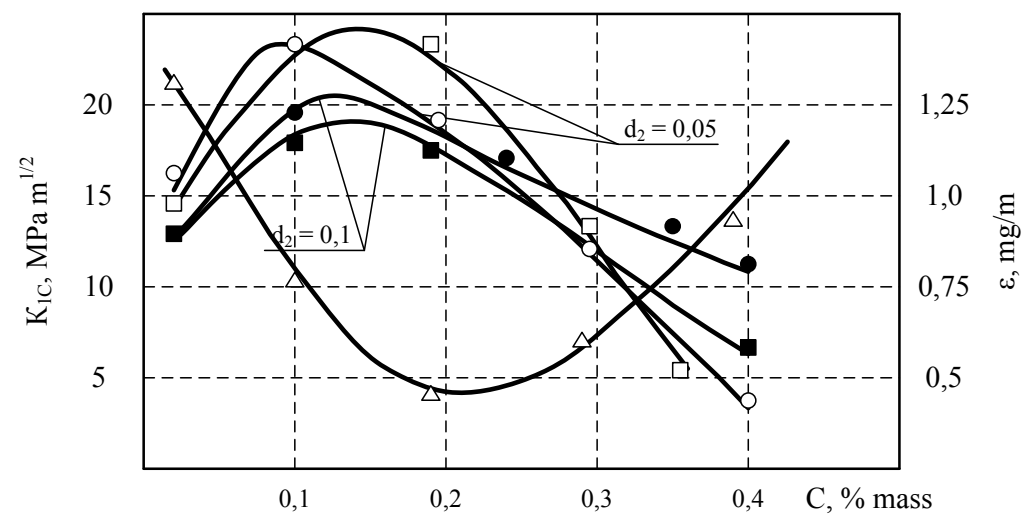

Fig. 3. Effect of nanoparticle size $\left(\mathrm{d}_{2}\right)$ on the fracture toughness $\left(\mathrm{K}_{1 \mathrm{C}}\right)$ of the composite. WC-Co - nano $\mathrm{Al}_{2} \mathrm{O}_{3}$ $(\bullet-$ calculation; $\square-$ experiment) and wear rate, $\varepsilon(\Delta)$

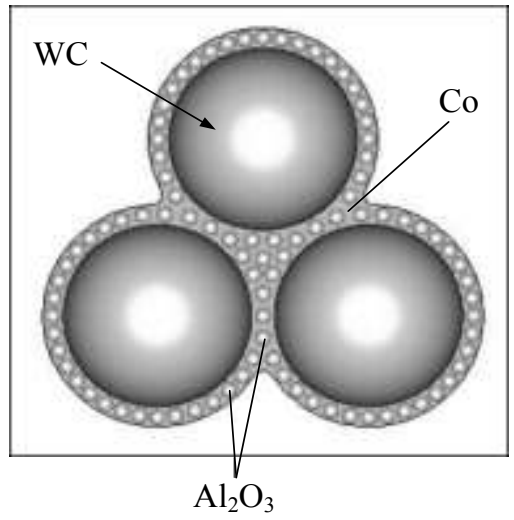

a)

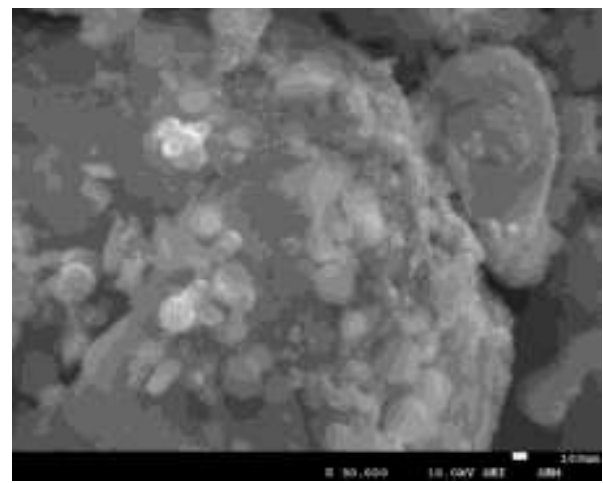

c)

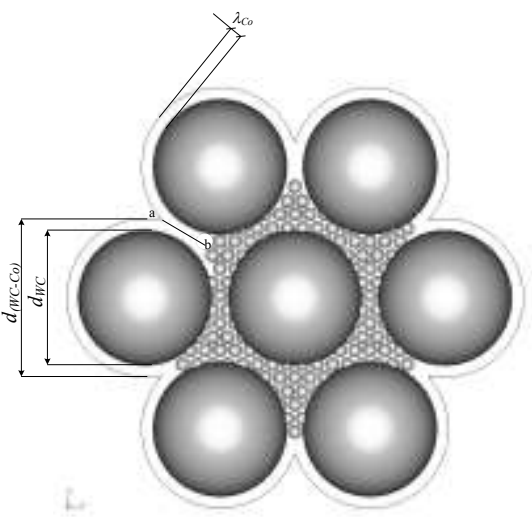

b)

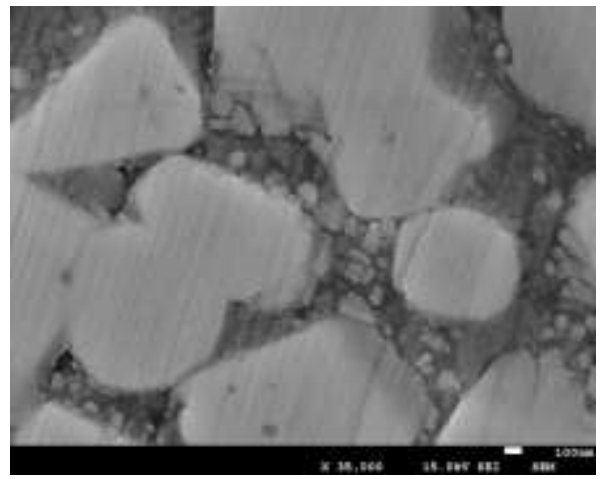

d)

Fig. 4 Stereological model and microstructure

$\mathrm{a}, \mathrm{b}$ ) sheme of packing; c) surface of "green" specimen (sintering themperature $1100{ }^{\circ} \mathrm{C}$ )

d) surface of sintered compound $-1370{ }^{\circ} \mathrm{C}$

Experimental methods established that the nanoparticles of $\mathrm{Al}_{2} \mathrm{O}_{3}$ ceramics in the amount of $0.05-0.25 \%$ by mass not only dispersly hardened the cobalt interlayer (the microhardness $\mathrm{H} \mu$, measured by the nanoindentation microhardness method, increases up to $22.01 \mathrm{GPa}$ ), but also provided the increase of strength (up to 25\%), fracture toughness according to Palmqvist (up to $50 \%$ ), reduction of abrasive wear $\sim 1.5$ times. The minimum values of wear are observed approximately in the same areas of additives $(\sim 0.25 \%$ by weight $)$, which provide the increase of 
strength. The results of calculations, based on the proposed model, show a satisfactory convergence of the calculated data with the experimental ones [7]. An additional contribution to increasing of the material wear resistance is apparently made by the increased resistance to abrasion of the alumina itself $\left(\mathrm{H} \mu \mathrm{Al}_{2} \mathrm{O}_{3}-18-20 \mathrm{GPa}\right)$. To a large extent, the increase of the overall level of strength properties is due to the inhibitory effect of nanoadditives, the average size of the carbide grain decreases monotonically with increasing concentration. The hardness and density parameters of the material do not differ significantly from the base material and are at the level: but the values of the microhardness of the interlayer of binder material - cobalt, which was estimated with the help of nanoindentation, are slightly increased, since the known effect of dispersive hardening at the level of structural fragments $\left(\mathrm{Co}-\mathrm{Al}_{2} \mathrm{O}_{3}\right)$ is realized. On the basis of the experimentally obtained positive results and the revealed features of the structure formation of heterophase carbide composites, the geometric model described in detail $[4,8]$ was refined and corrected, including the known and new density positions packaging of bimodal and polymodal dispersed systems. A new model of heterogeneous carbide structures assumes the use of composite submicron powders (WC-Co), obtained by various methods, which provides the maximum packing density and high homogeneity of the mutual distribution of phase constituents of the composite (Fig. 4). In the experimental part of the work, the composite powders, obtained by conventional chemical deposition on a carbon carrier in combination with a microwave action [6] were used.

On the basis of a new stereological model (Fig. 4), the estimated calculations of the nanoparticles additives needed to obtain compactings with the highest packing density were determined. The results of the complex parametric studies show that due to using composite carbide powders and modifying by the nanoparticles, the principle known in material science as "composition-structure-properties" is shown.

Table 1 - Propities of hard metal based on (WC-Co) composite powders

\begin{tabular}{|c|c|c|c|c|c|c|c|c|}
\hline \multirow[t]{2}{*}{ Sample } & \multicolumn{2}{|c|}{$\begin{array}{l}\text { Composition } \\
\text { of hardmetal } \\
\text { based on WC }\end{array}$} & \multicolumn{2}{|c|}{$\begin{array}{c}\text { Technologies of } \\
\text { sintering } \\
\text { (vacuum) }\end{array}$} & \multirow[t]{2}{*}{$\begin{array}{c}\text { Grain } \\
\text { size, } \\
\mathrm{d}_{\mathrm{WC}}[\mu \mathrm{m}]\end{array}$} & \multirow{2}{*}{$\begin{array}{l}\text { Transverse } \\
\text { rupture } \\
\text { tougness } \\
\sigma_{\mathrm{b}}[\mathrm{MPa}]\end{array}$} & \multirow[t]{2}{*}{$\begin{array}{l}\text { Abrasive } \\
\text { wear } \varepsilon \\
{[\mathrm{mg} / \mathrm{m}]}\end{array}$} & \multirow{2}{*}{$\begin{array}{c}\text { Fracture } \\
\text { toughness } \\
\mathrm{K}_{1 \mathrm{c}} \\
{[\mathrm{MPa} .} \\
\left.\mathrm{m}^{1 / 2}\right]\end{array}$} \\
\hline & Co & $\mathrm{Al}_{2} \mathrm{O}_{3}$ & $\mathrm{~T}\left[{ }^{\mathrm{O}} \mathrm{C}\right]$ & $\mathrm{t}[\mathrm{min}]$ & & & & \\
\hline 1 & 8 & - & 1450 & 60 & $2,4-2,7$ & 1800 & 1,22 & 10 \\
\hline 2 & 8 & 0,25 & 1420 & 60 & $0,9-2,4$ & 2400 & $0,55-0,6$ & 20 \\
\hline $3 *$ & 8 & 0,25 & 1370 & 30 & $0,6-2,0$ & 2700 & 0,3 & 22 \\
\hline
\end{tabular}

The use of composite submicron powders (WC-Co) in combination with the modification of $\mathrm{Al}_{2} \mathrm{O}_{3}$ (inhibitors) by nanoparticles is an effective starting method for improving the quality of nanostructured carbide composites (Table 1). Comparison of the results of the calculated (by model) and experimental researches show a satisfactory agreement of the predicted microstructure parameters and the strength properties with those that were previously achieved.

\section{References}

[1] C.J.R. González Oliver, E.A. Álvarez, J.L. García, Kinetics of densification and grain growth in ultrafine WC-Co composites, Int. Journal of Refractory Metals and Hard Materials 59 (2016) 121-131.

[2] Fang Zak Z., Wang Xu, Taegong Ryu, Kyu Sup Hwang, Sohn H.Y., Synthesis, sintering, and mechanical properties of nanocrystalline cemented tungsten carbide, A review, Int. Journal of Refractory Metals \& Hard Materials. 27 (2009) 288-299. 
[3] P. Cholsong, L. Ji, G. Zhimeng, Microstructure and properties of ultrafine WC-10 Co composites with chemically doped VC, Rare metals. T. 30, № 2 (2011) 183-188.

[4] Gordeev, Y. I., Abkaryan, A. K., Binchurov, A. S., and Jasinski, V. B. Design and Investigation of Hard Metal Composites Modified by Nanoparticles, Advanced Materials Research. 1040 (2014) 13-18.

[5] D. Vollath and D.V. Szabo, Coated nanoparticles: A new way to improved nanocomposites, Journal of Nanoparticle Research. 1 (1999) 235-242.

[6] Nikolaenko I.V., Kedin N.A., Shveikin G.P, Polyakov E.V. Microwave sysnthesis of ultrafine and nanosized powders of tungsten oxide and carbide. International Journal of Materials Research. Vol. 105, No. 3 (2014) 314-317.

[7] Godse, R. and Gurland, J., Applicability of the critical strength criterion to WC-Co, J. Mater. Sci. Eng. A. 106 (1988) 331-336.

[8] Gordeev Y. I., Abkaryan A. K., Binchurov A. S., Lepeshev A. A., Yasinski V. B., Influence of Additives of Nanoparticles on Structure Formation of Fine-Grained Hardmetals, Key Engineering Materials. 743 (2017) 3-8.

[9] Dvilis E.S., Khasanov O.L., Bikbaeva Z.G., Polisadova V.V., Struts V.K., Omarov G.Z., Khasanov A.O. Pattern of the B4C Ceramics Surface Deformation at Local Loading /, // Advanced Materials Research. 872 (2014) 60-64. 